\title{
Ciclagem de Nitrogênio em Sistemas de Integração Lavoura-Pecuária
}

\author{
Nitrogen cycling in crop-livestock systems
}

\author{
Paulo Hentz ${ }^{* 1}$, Nathália Leal Carvalho², Leandro Vinícius Luz ${ }^{3}$ e Afonso Lopes Barcellos ${ }^{4}$ \\ 1,2Universidade de Passo Fundo, Passo Fundo, Brasil. \\ ${ }^{3}$ Universidade Federal de Santa Maria, Santa Maria, Brasil. \\ ${ }^{4}$ Universidade do Norte do Paraná, Londrina, Brasil.
}

\begin{abstract}
Resumo
Entende-se a ciclagem como o movimento dos nutrientes entre os diversos compartimentos (atmosfera-plantaanimal-solo) do sistema de produção agropecuária. A associação do sistema integração lavoura-pecuária com plantio direto possibilita alta entrada de resíduo vegetal pelo uso de culturas e pastagens tanto gramíneas como leguminosas as quais permitem a disponibilização mais rápida e intensa ou lenta e gradual de nutrientes ao sistema, principalmente na camada superficial. Estudos mostram que $60 \%$ a 70\% do nitrogênio encontrado na biomassa vegetal é reciclado e novamente absorvido pelas plantas no cultivo. A quantidade de ciclagem de nutrientes pelo animal é definida pela intensidade de pastejo. Em geral, quanto mais animais por unidade de área maior será a ciclagem de nutrientes, porém haverá menor fixação de nutrientes em produto de orígem animal por unidade de forragem ingerida, e ambas as situações são afetadas pela intensidade de pastejo que pode contribuir com o retorno de nutrientes pelas fezes por bovino de $500 \mathrm{~kg}$ de peso vivo ao sistema, com valores estimados de 22, $1 \mathrm{~g}$ de $\mathrm{N}, 10,06 \mathrm{~g}$ de $\mathrm{P}, 6,12 \mathrm{~g}$ de $\mathrm{K}, 21,70 \mathrm{~g}$ de Ca e 9, $47 \mathrm{~g}$ de $\mathrm{Mg}$.
\end{abstract}

Palavras-chave: biomassa, decomposição, desenvolvimento sustentável.

\begin{abstract}
Cycling is the movement of the nutrients between the different compartments (atmosphere-plant-animal-soil) of farm systems. The combination of integrated crop-livestock system with tillage enables high input plant residue by use of both crops and pasture grasses such as legumes which allow providing more rapid and intense or slow and gradual nutrient system, especially in the surface layer. It is estimated that $60 \%$ to $70 \%$ of the nitrogen found in the vegetable biomass is recycled and again absorbed by plants in cultivation. The amount of nutrient cycling by animals is defined by the intensity of grazing. In general, the more animals per unit area greater nutrient cycling, however there will be less fixation of nutrients in animal products per unit of forage intake, and both situations are affected by grazing intensities that can contribute to nutrient intake per cattle faeces system with estimated values of $22.1 \mathrm{~g}$ of nitrogen, $10.06 \mathrm{~g}$ of $\mathrm{P}, 6.12 \mathrm{~g}$ of $\mathrm{K}, \mathrm{Ca}$ and $21,70 \mathrm{~g} 9,47 \mathrm{~g}$ of $\mathrm{Mg}$.
\end{abstract}

Keywords: decomposition, biomass, sustainable development. 


\section{Introdução}

$\mathrm{E}$ ntende-se a ciclagem como o movimento (fluxo) dos nutrientes entre os diversos compartimentos (atmosfera-planta-animal-solo) do sistema de produção agropecuária. O conhecimento da ciclagem é importante para o uso eficiente dos nutrientes do solo, dos resíduos e dos fertilizantes no sistema de produção, com especial ênfase para integração lavoura-pecuária (ILP).

As pesquisas sobre ciclagem de nutrientes em sistemas de produção ILP (KOZLINSKI, 2009) ainda são bastante incipientes no Brasil, e as existentes abordam o fluxo entre compartimentos do sistema, que consiste basicamente na decomposição de resíduos de palhadas, excreta e a consequente liberação de nutrientes (BORTOLLI, 2010). De acordo com Landers (2007), a implantação de pastagens em rotação com culturas cultivadas em sistemas de plantio direto (PD) otimiza ainda mais as características benéficas da conservação do solo, principalmente em razão das pastagens em sequestrar carbono (C), mas também pelo aumento da biodiversidade, melhoria da ciclagem de nutrientes e redução dos riscos econômicos (MORAES et al., 2007).

A moderna agricultura do Brasil envolve genótipos que possibilitam alto potencial produtivo com maiores demandas de extração e exportação de nutriente e desta forma traz a nova visão sobre o gerenciamento do fornecimento de nutrientes ao sistema de produção agrícola, ou seja, havendo a necessidade ainda maiores de aporte de nitrogênio $(\mathrm{N})$ ao sistema, seja na forma de fertilizantes ou fixação biológica. A adubação bem definida em termos qualitativos e quantitativos é pré-requisito tão mais importante quanto mais intenso o sistema de produção adotado para se alcançar altas produtividades (ROSOLEM, 2003).

Entre os sistemas com maior eficiência de extração de nutrientes vale destaque para a ILP, em razão de suas altas produtividades. Desta forma, o conhecimento da ciclagem dos nutrientes em sistemas de produção ILP é de extrema importância, pois as perdas e adições de carbono e nutrientes modificam a dinâmica do solo. Assim a ILP aparece como uma estratégia promissora para desenvolver sistemas de produção sustentáveis ao longo do tempo, desde que respeitado a reposição dos nutrientes a fim de manter a fertilidade do solo, uma vez que este sistema envolve intensiva ciclagem de nutrientes.

Um dos mecanismos que podem quantificar a ciclagem de nutrientes é o balanço de nutrientes representado em razão da quantidade de nutrientes que entra no sistema agrícola pelos processos de adubação, correção do solo e fixação biológica subtraindo da quantidade que deixa o sistema pela exportação da colheita. Para que a produção agrícola seja sustentável é necessário que os nutrientes removidos do solo sejam repostos por meio da aplicação de fertilizantes orgânicos ou minerais e que alcancem elevados índices de aproveitamento (NASCIMENTO \&
CARVALHO, 2011). O conhecimento da ciclagem dos nutrientes nos agrossistemas resulta em sua utilização mais eficiente pelas culturas e na redução dos impactos negativos ao ambiente (ROSOLEM, 2003).

Entender a ciclagem de nutrientes no sistema de produção ILP permitirá que o produtor agrícola possa explorar o potencial genético produtivo de cada cultura, bem como manter a qualidade ambiental, pois preservará a fertilidade de seu solo em razão da entrada de nutrientes no sistema de forma específica (CUNHA et al., 2010). Lembrando que há a necessidade muito alta de nutrientes neste sistema de produção em razão das altas produtividades alcançadas, o que demandará elevados níveis de nutrientes para manter o equilibirio do sistema (VITOUSEK et al., 2009).

Para entender a ciclagem de nutrientes no sistema ILP, há a necessidade de conhecer os resíduos culturais que permanecem na superfície do solo, os quais constituem importante reserva de nutrientes, cuja disponibilização pode ser rápida e intensa (ROSOLEM et al., 2007), ou lenta e gradual, conforme a interação entre os fatores climáticos, principalmente precipitação pluvial e temperatura, atividade macro e microbiológica do solo e qualidade e quantidade do resíduo vegetal (OLIVEIRA et al., 2002).

Para que uma espécie seja eficaz na ciclagem de nutrientes deve haver sincronia entre o nutriente liberado pelo resíduo da planta de cobertura e a demanda da cultura de interesse comercial, cultivada em sucessão. Sendo que em alguns sistemas a liberação de nutrientes pode coincidir com a maior demanda nutricional da cultura quando se utiliza consorciação entre espécies, de preferência gramíneas e leguminosas. Lembrando que quanto maior a quantidade de palha em contato com o solo, maior a velocidade de decomposição dos resíduos vegetais (CRUSCIOL et al., 2008).

Para compensar essa perda de nutrientes no solo, torna-se necessário o uso de técnicas que aumentem o acúmulo de fitomassa por parte das plantas de cobertura e que sincronizem a decomposição da palhada e a taxa de liberação dos nutrientes com a demanda das culturas anuais semeadas em sucessão (GAMA-RODRIGUES et al., 2007).

Para eficiente fornecimento de nutrientes é essencial que ocorra sincronia entre o nutriente liberado pelos restos culturais das espécies de cobertura e a demanda da cultura implantada em sucessão (STUTE \& POSNER, 1995); caso contrário, podem ocorrer perdas de nutrientes por lixiviação (LARA-CABEZAS et al., 2000).

\section{Entradas de Nutrientes na Agricultura Brasileira}

Na agricultura, a entrada de nutrientes pode compreender diversas origens: fixação biológica de $\mathrm{N}$, deposições atmosféricas de $\mathrm{N}$ e enxofre (S), precipitação 
de cinzas vulcânicas, intemperização dos solos, adição de fertilizantes orgânicos, minerais e organominerais.

A entrada de fertilizantes no ano de 2008 na agricultura brasileira atingiu total de 22,4 milhões de toneladas $(\mathrm{t})$, correspondendo a 2.502.245, 3.195.934, 3.688.611 milhões de toneladas de $\mathrm{N}$, $\mathrm{P} 2 \mathrm{O} 5$ e $\mathrm{K} 2 \mathrm{O}$ respectivamente (ANDA, 2009; YAMADA \& LOPES, 1998).

A mineralização dos restos de culturas de cobertura promove a entrada de nutrientes no sistema, os quais são disponibilizados em diferentes velocidades, sem considerar outras entradas, como a água da chuva; e estes tem suas saídas por volatilização, lixiviação, percolação e escoamento superficial. A preocupação com os meios de produção, com o ambiente e com os custos de produção da atividade pecuária e agrícola, são fatores que tem levado à pesquisa e aos produtores a necessidade da adoção de técnicas de cultivo mais econômicas e sustentáveis (NASCIMENTO \& CARVALHO, 2011)

\section{Nitrogênio}

O N é o macronutriente exigido em maior quantidade por grande parte das culturas agrícolas, no entanto o fator que dificulta a recomendação de adubação de forma eficiente é razão de sua dinâmica no solo, que envolve reações como: imobilização/mineralização; nitrificação/desnitrificação; lixiviação/volatilização; adsorção/sorção; entre outros mecanismos, os quais são provenientes da interação entre microrganismos e colóides do solo e mediados por fatores climáticos de difícil previsão. Outra dificuldade está relacionada a ele não estar presente na análise básica de rotina de solos em razão das dificuldades metodológicas em avaliar sua disponibilidade (CANTARELLA \& DUARTE, 2004).

Diante deste grande número de reações que o $\mathrm{N}$ pode desempenhar no solo seu aproveitamento quando da utilização de formas minerais fica na ordem entre 11 a $68 \%$ do $\mathrm{N}$ utilizado (LARA-CABEZAS et al., 2000; GIACOMINI et al., 2009), sendo a outra parte atribuída ao $\mathrm{N}$ orgânico do solo, fração que corresponde a $95 \%$ do $\mathrm{N}$ total do solo, os quais podem ter alta ou baixa labilidade, dependendo do tipo de cadeia orgânica em que esteja inserido. O sincronismo entre a liberação de $\mathrm{N}$ dos resíduos orgânicos e a demanda em $\mathrm{N}$ pelas plantas é fundamental, tanto do ponto de vista da produtividade como da redução do risco de contaminação ambiental via volatilização de amônia, lixiviação de nitrato e emissão de N2O (GIACOMINI \& AITA, 2007).

$\mathrm{O} \mathrm{N}$ na planta promove diversas alterações fisiológicas, como o número, tamanho, massa e taxa de aparecimento de perfilhos e folhas, além do alongamento do colmo, fatores estes importantes na produção de massa seca e valor nutritivo da planta forrageira, além de ser necessário à síntese de ácidos nucléicos, proteínas, hormônios, clorofila e vários outros compostos essenciais ao desenvolvimento das plantas (SILVA \&
MONTEIRO, 2007).

Estima-se que $60 \%$ a $70 \%$ desse nutriente encontrado na biomassa vegetal sejam reciclado e novamente absorvido pelas plantas no cultivo seguinte (SPAIN \& SALINAS, 1985). Além disso, a adubação nitrogenada em pastagens pode melhorar o desempenho de culturas semeadas em sucessão, devido ao aproveitamento de $\mathrm{N}$ residual, como observado em trabalho desenvolvido por Assmann et al. (2003).

De acordo com Kluthcouski et al. (2005), o N que é disponibilizado às plantas provém da matéria orgânica do solo (MOS), da reciclagem dos resíduos de culturas anteriores e dos fertilizantes nitrogenados de origem mineral ou orgânica. Nas últimas décadas o Brasil vem registrando mudanças no setor agropecuário, pela incorporação de processos intensivos de modernização nos sistemas de produção, frente às demandas impostas pela sociedade, conferindo maior produtividade e competitividade e com mínimo impacto no ambiente (NASCIMENTO \& CARVALHO, 2011). Nesse contexto, o sistema ILP, justifica-se pela união benéfica dos fatores agronômicos, econômicos, sociais e ambientais (MARTHA JÚNIOR et al., 2006).

A aplicação em larga escala de fertilizantes, muitas vezes exigida pelos sistemas agrícolas intensivos, vem se tornando impraticável por motivos econômicos e, ou, ambientais. É necessário o estudo de modelos agrícolas menos dependentes do uso de insumos e que reduzam o custo de produção tornando-os mais eficientes. O nitrogênio é responsável por grande parte do gasto com as adubações, além de ser um dos elementos que mais contribui para a contaminação de lençóis freáticos (CARVALHO \& ZABOT, 2012).

A adubação nitrogenada é considerada um dos principais fatores limitantes da produção, interferindo diretamente nos componentes de rendimento da cultura. Vários fatores ambientais interferem nessa eficência de mineralização do nitrogênio orgânico (LIU et al., 2011) e provavelmente o teor de matéria orgânica seja a que melhor representa a qualidade deste solo e disponibilidade de N (MELLO et al., 1989), podendo ser alcançada pela utilização de culturas que produzam alta adição de biomassa, em sistema de plantio direto, com integração lavoura-pecuária.

A mineralização e nitrificação do $\mathrm{N}$ ocorre simultaneamente em solos, e seu balanço, muitas vezes determina o nitrogênio disponível para absorção pelas plantas ou o nitrogênio é perdido via desnitrificação e lixiviação (LIU et al., 2011). A quantidade de nitrogênio existente no solo, na maioria dos sistemas de produção do Sul do Brasil não é suficiente para satisfazer a demanda total deste nutriente para as culturas (SPERA et al., 2009).

A associação do sistema ILP com o PD combinado possibilita alta entrada de resíduo vegetal pelo uso de culturas e pastagens (ANGHINONI et al., 2011; LOSS et al., 2011.), o que permite suportar maior estoque de $C$ Orgânico total especialmente na camada de 0,0-30cm, e N 
na camada de 0,0-20 cm em relação à área sem pastagem no sistema plantio direto (LOSS et al., 2012).

Em sistemas de ILP-PD ocorre aporte diferenciado de resíduos vegetais em relação aos sistemas puros de produção de grãos, tanto na superfície quanto no perfil do solo pelas raízes (SOUZA et al., 2008; SOUZA et al., 2009; SOUZA et al., 2010). Desta forma, a intensidade de pastejo tem grande influência na quantidade e distribuição dos dejetos excretados pelos animais. Diante disso, se verifica que o aporte de C e N (total e na fração particulada), tanto em superfície quanto em profundidade, será influenciado pela lotação animal e, por este motivo, a altura de manejo do pasto passa a ser fator de grande importância na dinâmica da matéria orgânca do solo (MOS), e nutrientes.

O tempo tem efeito importante na avaliação de sistemas ILP-PD, uma vez que o comportamento da MOS é distinto quando comparado a sistemas puramente de produção de grãos. Aumentos de até $3,47 \mathrm{Mgha}^{-1}$ têm sido observados no estoque de $\mathrm{C}$ após três anos, representando incremento médio anual de 1,16 $\mathrm{Mgha}^{-1}$, o que é considerado alto. Para o $\mathrm{N}$ esse aumento no estoque chega a $345 \mathrm{kgha}^{-1}$, representando incremento anual médio de $115 \mathrm{~kg} \mathrm{ha}^{-1}$ (CORAZZA et al., 1999).

\section{Aporte de $\mathrm{N}$ ao Sistema e Ciclagem de $\mathrm{N}$ por Plantas}

O uso de plantas de cobertura é uma excelente alternativa para aumentar a sustentabilidade dos sistemas de produção, podendo restituir quantidades consideráveis de nutrientes aos cultivos, uma vez que essas plantas absorvem nutrientes das camadas subsuperficiais do solo e os liberam, posteriormente, na camada superficial pela decomposição dos seus resíduos. Assim, a decomposição de resíduos das culturas atuam na ciclagem de nutrientes e o conhecimento de sua dinâmica é fundamental para a compreensão do processo (AIDAR \& KLUTHCOUSKI, 2003).

Em virtude deste fato, a velocidade de decomposição dos resíduos culturais determina o tempo de permanência da cobertura morta na superfície do solo. Assim, quanto mais rápida for a sua decomposição, maior será a velocidade de liberação dos nutrientes, diminuindo, entretanto, a proteção do solo. Por outro lado, quanto mais altos forem os conteúdos de lignina e a relação $\mathrm{C} / \mathrm{N}$ nos resíduos, tanto mais lenta será a sua decomposição.

A adubação nitrogenada pode melhorar o desempenho de culturas semeadas com objetivo de pastagem e após sua sucessão poderá haver o aproveitamento de $\mathrm{N}$ residual, proveniente da biomassa seca de raízes e parte aérea remanescente (ASSMANN et al., 2003).

O uso de espécies forrageiras como as do gênero Urochloa para a formação de palha vem despertando o interesse de muitos agricultores e pesquisadores. Estas gramíneas são de grande potencial na manutenção da palha sobre o solo devido a sua alta relação C/N e lignina/N total, o que retarda sua decomposição e aumenta a possibilidade de utilização em regiões quentes, como o Cerrado brasileiro. Estas espécies se destacam ainda pela excelente adaptação a solos de baixa fertilidade, facilidade de estabelecimento, considerável produção de biomassa o que proporciona excelente cobertura vegetal do solo (ANDRIOLI, 2004).

A decomposição de resíduos das culturas é uma variável importante na ciclagem de nutrientes em sistema plantio direto e o conhecimento de sua dinâmica é fundamental para a compreensão do processo, uma vez que o conhecimento desta ciclagem resultará em utilização mais eficiente dos nutrientes pelas culturas e principalmente na redução dos impactos negativos causados ao ambiente.

As taxas de decomposição das plantas de cobertura dependem da natureza do material vegetal, do volume, do tipo de solo, do manejo da cobertura e das condições climáticas, representadas, principalmente, pela pluviosidade e temperatura (KLIEMANN et al., 2006; VIOLA et al., 2013). De forma geral a decomposição das gramíneas é mais lenta, quando comparada a leguminosas e crucíferas, este comportamento está diretamente relacionado à relação $\mathrm{C} / \mathrm{N}$ e ao teor de lignina do material vegetal. No início do processo são decompostos açúcares e proteínas, restando para o fim o material recalcitrante (celulose e lignina) (WIEDER \& LANG, 1982).

Na condição onde houver maior velocidade de decomposição maior será a velocidade de liberação dos nutrientes, diminuindo, entretanto, a proteção do solo; por outro lado, quanto mais altos forem os conteúdos de lignina e a relação $\mathrm{C} / \mathrm{N}$ nos resíduos, tanto mais lenta será a sua decomposição (FLOSS, 2000). Pode-se, portanto, agrupar as espécies vegetais em duas classes, uma de decomposição rápida (leguminosas) e outra de decomposição lenta (gramíneas), sendo bem aceito ovalor de relação $\mathrm{C} / \mathrm{N}$ próximo a 25 , como referência de separação entre elas (WIEDER \& LANG, 1982).

As forrageiras apesar de exaurirem os nutrientes residuais deixados pelas lavouras na superfície do solo, reciclam os nutrientes do subsolo, preservam e permitem outra dinâmica a matéria orgânica e promovem a aração biológica do mesmo, decorrente da abundância e agressividade de seus sistemas radiculares e da atividade biológica decorrente (AIDAR \& KLUTHCOUSKI, 2003).

Em sistemas conservacionistas, como o PD, onde há a presença de resíduos vegetais na superfície do solo, acredita-se que a eficiência de recuperação do $\mathrm{N}$ pode ser melhorada ao se identificar o momento de liberação de $\mathrm{N}$ dos resíduos vegetais devido aos processos de mineralização e imobilização do $\mathrm{N}$ pela fauna microbiana do solo.

Apesar dos benefícios do efeito residual da adubação da cultura produtora de grãos na ILP serem descritos por (MARTHA JÚNIOR \& VILELA, 2007), há necessidade de adubação nitrogenada na cultura forrageira, 
não podendo esta ficar na dependência apenas do efeito residual da cultura produtora de grãos.

Barducci et al. (2009) apontaram que em sistemas de ILP, mesmo com a utilização de fertilizantes nitrogenados em semeadura e cobertura após a colheita há grande quantidade de palha proveniente do milho, a qual não supre a demanda de $\mathrm{N}$ pela cultura forrageira, vindo esta a competir diretamente pelo $\mathrm{N}$ do solo em razão dos microrganismos decompositores que irão condicionar a imobilização e mineralização subsequente, podendo a levar em alguns casos a deficiência deste elemento a cultura.

Como exemplo, pode-se citar que elevada relação $\mathrm{C} / \mathrm{N}$ da palhada do milho mobiliza maior quantidade de nitrogênio para a sua decomposição, tornando-o indisponível durante a fase inicial do trigo, o qual também é uma cultura exigente em nitrogênio (WENDLING et al., 2007).

De acordo com Martha Júnior et al. (2006), a eficiência de conversão do N-fertilizante em forragem, em pastagens de gramíneas tropicais na região do Cerrado, é em média de $26 \mathrm{~kg}$ de massa seca $\mathrm{kg}^{-1}$ de $\mathrm{N}$ aplicado, podendo, contudo, chegar a $83 \mathrm{~kg}$ de massa seca (MS) $\mathrm{kg}^{-1}$ de $\mathrm{N}$, sendo que as maiores eficiências médias foram observadas para as doses de até $150 \mathrm{kgha}^{-1} \mathrm{ano}^{-1} \mathrm{de}$ N. No estudo de Costa (2010) ocorreu variação de $81,5 \mathrm{~kg}^{-1}$ de massa seca $\mathrm{kg}^{-1}$ de $\mathrm{N}$ na testemunha até $20,8 \mathrm{~kg}^{-1}$ de MS $\mathrm{kg}^{-1}$ de $\mathrm{N}$ na dose de $200 \mathrm{kgha}^{-1}$ de $\mathrm{N}$, entretanto com produção de MS de 2.445 e $4.159 \mathrm{~kg} \mathrm{ha}^{-1}$, respectivamente.

Torres et al. (2005), avaliando a taxa de decomposição e liberação de nutrientes em diversas espécies de cobertura na região de Cerrado, durante dois anos agrícolas, verificaram valores de $\mathrm{N}$ acumulado por Brachiaria Brizantha de 130,8 a 41,6kgha-1 ${ }^{-1}$ com produtividades de massa seca em torno de 6,0 e 2,1 tha ${ }^{-1}$ apenas pela parte aérea da planta.

Em trabalhos realizados por Costa (2010), foi verificado que as doses crescentes de $\mathrm{N}$ fornecidas às espécies forrageiras após consórcio com o milho influenciaram os teores médios de $\mathrm{N}$ foliar do tecido vegetal, apresentando ajuste quadrático com o maior teor deste nutriente na dose de $181,7 \mathrm{kgha}^{-1}$ de $\mathrm{N}$.

Muitas vezes o valor elevado de $\mathrm{N}$ nas gramíneas deve-se à alta produção de fitomassa seca e na leguminosa à fixação biológica de $\mathrm{N}$, sendo que em alguns sistemas as gramíneas podem depositar mais $\mathrm{N}$ no solo que as leguminosas, como no caso do milheto (PRIMAVESI et al., 2002) e em ambas as ocasiões o $\mathrm{N}$ acumula-se em em compostos orgânicos, os quais ficam à disposição para ciclagem no sistema de produção ILP.

Lima et al. (2005), onde avaliaram o acúmulo de nutrientes pela palhada de diferentes espécies forrageiras e verificaram que o nutriente acumulado em maior quantidade, pelas espécies de sorgo de Guiné, milheto e painço, foi o K, sendo seguido por N, Ca, Mg e P. Esses maiores acúmulos de $\mathrm{K}$ confirmam a alta reciclagem desse elemento pelas gramíneas, o que pode favorecer a rotação e a sucessão com leguminosas fornecedoras de N (RAIJ et al., 1997).

Costa et al. (2010) trabalhando em condição de cerrado com plantas de ciclo estival, encontraram tempo de meia vida entre 90 e 120 dias após o manejo de corte em diferentes espécies, e aos 150 dias mostraram a seguinte ordem decrescente de decomposição: sorgo (Sorghum bicolor L. Moench) 80\%, estilosantes (Stylosanthes spp.) $72 \%$, guandu (Cajanus spp.) 65\%, capim-mombaça ( $\mathrm{Pa}$ nicum maximum Jacq vr. Mombaça) 64\%, milheto (Pennisetum americanum L. Reeke) 58\%, Brachiaria brizantha (U. brizantha) em cultivo exclusivo 56\% e em cultivo consorciado $48 \%$. Demonstrando ser esta prática muito benéfica para proteger o solo durante o desenvolvimento da cultura em sucessão, garantindo menor variação na temperatura do solo, maior umidade, no entanto ocorre a disponibilização de nutrientes de forma lenta em razão do processo de decomposição e mineralização do material vegetal.

Viola et al. (2013) verificaram que aos cem dias a ervilhaca (Vicia sativa L. Basionônio) apresentou decomposição de $71 \%$, seguida do nabo forrageiro (Raphanus sativus L.) com 70\%, tremoço (Lupinus albus L.) com $57 \%$ e ervilha forrageira (Pisum sativum) com 56\%. A maior velocidade de decomposição da ervilhaca pode ser atribuída ao maior ciclo desta espécie, sendo manejada antes do florescimento e, consequentemente, com menor relação $\mathrm{C} / \mathrm{N}$.

Torres et al. (2008), observaram maiores taxas de decomposição aos 42 dias após o manejo de corte com o gênero Urochloa e área de pousio (GAMA-RODRIGUES et al., 2007), verificaram em braquiária, $\mathrm{T}^{1} \frac{1}{2}$ para disponibilidade de N, P, Ca e Mg idade de 131, 112, 198 e 122 dias respectivamente.

A decomposição rápida no período inicial pode ser explicada devido ao elevado conteúdo de componentes de baixo peso molecular tais como açúcares, aminoácidos e proteínas e com o passar do tempo a velocidade de decomposição reduz em razão à acumulação de componentes recalcitrantes, tais como lignina, taninos e celulose (GIACOMINI et al., 2003; LUPWAYI et al., 2007).

Ulian et al. (2010), avaliaram três espécies de cobertura (sorgo forrageiro, milheto e U. brizantha cv. MG-5) quanto a produção de palha e tempo de decomposição, e observaram que, na 1aa avaliação, o sorgo e milheto apresentaram residual de palha em torno dede $25 \%$ da massa seca inicial aos 180 dias após o corte, valores inferiores aos $52 \%$ da decomposição da U. brizantha (Hochst. ex A. Rich.) R.D. Webster, estes resultados corroboram com os encontrados por Kliemann et al. (2006)

Ulian et al. (2008), verificaram que as percentagens de palha remanescente aos 120 dias após o corte foram de 70, 65,55 e $45 \%$, respectivamente para o sorgo, U. brizantha, milheto [Pennisetum americanum (L.) Leeke] e capim moa [Setaria italica (L.) P. Beauv.]. Valores superiores aos 45\% do milheto aos 150 dias após o corte encontrados por Andreotti et al. (2006), e 52\% da U. brizantha aos 150 dias 
após o corte verificados por (KLIEMANN et al., 2006).

Boer et al. (2007), avaliaram a ciclagem de nutrientes no Cerrado, utilizando plantas de cobertura semeadas na safrinha, constataram que a maioria dos nutrientes é liberada de forma precoce para aproveitamento da safra seguinte, em razão da acelerada decomposição dos resíduos vegetais.

Salton (2007) constatou que nos resíduos vegetais de milheto e braquiária existem altos teores de $\mathrm{N}$, além da grande quantidade de fitomassa produzida, chegando a representar uma disponibilidade potencial de 209 e $250 \mathrm{kgha}^{-1}$ de N, respectivamente. Já, Gomes Junior (2006) verificou retorno de $17 \mathrm{~kg}$ de $\mathrm{N}$ por tonelada de palhada para U. brizantha cv. MG-5.

Malavolta (1980) relatou valores de produção de massa seca da parte aérea de forrageiras variando de 13.000 a $25.000 \mathrm{~kg} \mathrm{ha}^{-1}$, os quais podem proporcionar valores extraídos entre 200 a 300,30 a 70 e 200 a $500 \mathrm{~kg} \mathrm{ha}^{-1}$ dos macronutrientes N, P e K. De acordo com (MAGALHÃES, 1997), a U. brizantha com seis toneladas de biomassa seca da parte aérea pode reciclar, aproximadamente, 62, 12 e $110 \mathrm{kgha}^{-1}$ de N, P e K respectivamente.

Santos et al. (2011) verificaram que em sistemas de produção ILP, onde usaram pastagens perenes para pastejo na estação fria (festuca [Festuca arundinacea] + trevo branco [Trifolium repens L.] + cornichão [Lotus corniculatus]) e pastagens perenes para pastejo na estação quente (pensacola [Paspalum notatum] + trevo vermelho $[T$. pratense $]+$ cornichão $[$ L. corniculatus $]$ ), houve um aumento no teor de MOS na camada de 0-5 $\mathrm{cm}$ quando comparado aos sistemas de produção que usavam trigo/soja, aveia branca/soja e ervilhaca/milho, ainda, trigo/soja, aveia branca/soja e pastagem de aveia preta + ervilhaca/milho. Espera-se desta forma que estes sistemas mais eficientes para incremento de MOS venham a proporcionar melhor ciclagem de nutrientes e aumento do teor de $\mathrm{N}$ dos sistemas, e normalmente tem sido adotado como estratégia para se atingir melhor estabilidade de produção (BALBINOT JR. et al., 2009; CALEGARI et al., 2009; BODDEY et al., 2010).

Diversos trabalhos demonstram o potencial da ervilhaca comum (AITA et al., 2001; GIACOMINI et al., 2003b; ALMEIDA \& CÂMARA, 2007), ervilha forrageira e de tremoço (AITA et al., 2001) e nabo forrageiro (ALMEIDA \& CÂMARA, 2007; LIMA et al., 2007), em substituir ou complementar a adubação nitrogenada, com contribuições de nitrogênio que variam entre 76 e $240 \mathrm{kgha}^{-1}$, quando cultivados anteriormente a cultura do milho. Cultivadas em sucessão ao milho, a ervilha forrageira e o nabo forrageiro podem contribuir com até $80 \mathrm{kgha}^{-1}$ de N para o trigo (KOCHHANN et al., 2003; VOSS et al., 2004).

Viola et al. (2013) observaram que a relação C/N de nabo forrageiro, ervilha forrageira, ervilhaca comum e tremoço, influencia na taxa de mineralização que tende a ser superior à imobilização, com maior disponibilização de nitrogênio durante o processo de decomposição dos restos vegetais, o que é benéfico ao trigo, cultivado em sucessão. Outros estudos apontam estas espécies com relação $\mathrm{C} / \mathrm{N}$ adequada para o cultivo antecedendo gramíneas (HEINRICHS et al., 2001; AITA et al., 2001;LIMA et al., 2007). Ao contrário, a elevada relação $\mathrm{C} / \mathrm{N}$ da palhada do milho (64) e do feijoeiro (44) pode acarretar em maior imobilização de $\mathrm{N}$.

Em relação ao acúmulo de N, Viola et al. (2013) relataram que as maiores taxas foram observadas para a ervilha forrageira com $209 \mathrm{kgha}^{-1} \mathrm{e}$ tremoço com $162 \mathrm{kgha}^{-1}$, sendo estes resultados justificados à elevada produção de MS e concentração deste nutriente. Aita et al. (2001) observaram acúmulos de 69 e $113 \mathrm{kgha}^{-1}$ de $\mathrm{N}$, respectivamente, para a ervilha forrageira e tremoço, estes resultados corroboram com Giacomini et al. (2003b) e confirmam a importância destas espécies quanto ao fornecimento deste nutriente ao sistema.

Viola et al. (2013) pode-se observar que as maiores liberações de $\mathrm{N}$ ocorreram nos primeiros 14 dias, e foram observadas liberação para ervilhaca comum de 51\%, ervilha forrageira $39 \%$ e o tremoço $38 \%$. Aos 28 dias após, o tremoço e a ervilhaca comum contribuíram com, respectivamente, 84 e 63kgha-1 de nitrogênio, enquanto a palhada de milho contribuiu com apenas $24 \mathrm{kgha}^{-1}$, e tais espécies ainda contribuíram com a totalidade de $111,56,77$ e $34 \mathrm{kgha}^{-1}$ de N, respectivamente.

A quantidade de $\mathrm{N}$ presente no compartimento mais recalcitrante foi superior na palhada de milho, com meia vida de 90,3 dias. O nabo forrageiro levou 40,6 dias para liberar $50 \%$ do N presente na MS, o que é desejável para a dinâmica de fornecimento desse nutriente à cultura cultivada em sucessão. A ervilhaca comum proporcionou $56,5 \%$ do N presente no compartimento mais facilmente decomponível, levando apenas 4,5 dias para liberar $50 \%$ do $\mathrm{N}$ total contido nos resíduos vegetais (VIOLA et al. 2013).

O milheto caracteriza-se por elevada produção e persistência da palhada sobre o solo, que pode ultrapassar $14 \mathrm{Mgha}^{-1}$; e alta capacidade de extração de nutrientes, com alta eficiência na ciclagem de $\mathrm{N}$ e $\mathrm{K}$, que podem atingir valores de 205 e $215 \mathrm{kgha}^{-1}$, respectivamente (CRUSCIOL \& SORATTO, 2009). Já a crotalária (Crotalaria juncea L.), apresenta boa produção de fitomassa, superior a $8 \mathrm{Mgha}^{-1}$ (MENEZES et al., 2009), serve como adubo verde, com fixação de $\mathrm{N}_{2}$ atmosférico que pode chegar a 150 a165kgha-1 (WUTKE, 1993).

\section{Entrada de Animais no Sistema}

A entrada do animal no sistema produtivo modifica os fluxos entre os compartimentos, por haver ingestão de nutrientes, via consumo da forragem, sua digestão e posterior retorno ao sistema (CAVALCANTE, 2011), ocorrendo a ciclagem dos nutrientes pelo material orgânico, o que resulta em nova dinâmica dos nutrientes entre os compartimentos do sistema. Vale ressaltar que o 
cálculo de ciclagem de nutrientes na ILP quando envolve o pastejo por bovinos deve levar em consideração que um bovino adulto pode excretar $28 \mathrm{~kg}$ de fezes $(0,4 \% \mathrm{~N}$, $0,2 \%$ P e $0,8 \% \mathrm{~K})$ e $9 \mathrm{~kg}$ de urina $(1,1 \%$ de $\mathrm{N}, 0,01 \%$ de $\mathrm{P}$ e $0,96 \%$ de K) por dia, contribuindo substancialmente na ciclagem destes nutrientes para o solo. A concentração média de $\mathrm{N}, \mathrm{P}_{2} \mathrm{O}_{5}$ e de $\mathrm{K}_{2} \mathrm{O}$ encontrados em piquetes pastejados por bovinos segundo Petterson et al. (1956) foram 852, 393 e 494kgha-1 respectivamente (BIERMAN et al., 1999; WILKINSON \& LOWREY, 1973).

Em pastagem de Urochloa spp. BRAZ et al. (2002) avaliaram a reciclagem de nutrientes e observaram concentrações de N, P, K, Ca e Mg nas fezes de novilhas com peso médio inicial de $300 \mathrm{~kg}$ de peso vivo em torno de 11,$2 ; 5,1 ; 3,1 ; 11,0$ e $4,8 \mathrm{~g} / \mathrm{kg}$, respectivamente. O retorno diário de nutrientes pelas fezes, por animal, foi estimado em 22,10g de $\mathrm{N}, 10,06 \mathrm{~g}$ de $\mathrm{P}, 6,12 \mathrm{~g}$ de $\mathrm{K}, 21,70 \mathrm{~g}$ de Ca e $9,47 \mathrm{~g}$ de $\mathrm{Mg}$, o retorno de N, P, K e S das fezes de animais em pastejo de áreas com produtividade de MS de $15.000 \mathrm{kgha}^{-1}$ é de $100,45,78$ e $14 \mathrm{kgha}^{-1}$, respectivamente (HAYNES \& WILLIAMS, 1993).

Dessa forma, o solo pode ser considerado o compartimento centralizador de processos, maior ou menor, das modificações do sistema (ANGHINONI et al., 2010; CARVALHO et al., 2010). É importante esclarecer que pequena parte dos nutrientes aportados no sistema é exportada pela produção animal como carne (SOUZA et al., 2009). A quantidade de nutrientes exportados através de produtos animais carne, leite e lã em sistemas de pastejo é muito reduzida em relação ao total reciclado, pois 60 a $99 \%$ dos nutrientes ingeridos retornam ao pasto na forma de excreta. A maior remoção ocorre com Ca e P (WILKINSON \& LOREY, 1973).

Corsi \& Martha Júnior (1997), mensurou em sistema leiteiro com produção igual a $8.000 \mathrm{Kgdeleiteha}^{-1} \mathrm{ano}^{-1}$ a utilização de N, P e K foi equivalente a 42,8 e $11 \mathrm{~kg}$, respectivamente, e em sistema de produção de corte com $500 \mathrm{~kg}$ de peso vivo ha ${ }^{-1} \mathrm{ano}^{-1} \mathrm{os}$ valores de exportação desses nutrientes foram respectivamente, 12 , 4 e $1 \mathrm{kgha}^{-1} \mathrm{ano}^{-1}$.

Em bovinocultura leiteira, o uso de alimentos concentrados de alta qualidade (alto teor de proteína bruta e digestibilidade), no arraçoamento permite conversão alimentar para produção de leite com $74 \%$ de aproveitamento de N, enquanto que os $26 \%$ restantes permanecem nas excretas. $\mathrm{O}$ animal em pastejo, por sua vez, pode ser considerado o elemento catalisador que cicla o material vegetal e modifica profundamente a dinâmica dos nutrientes nos diversos compartimentos do sistema (ALVAREZ et al., 2013).

O pastejo influencia os processos de mineralização e imobilização de N, em razão de facilitar a decomposição de matérias de cadeias carbônicas maiores (lignina) em cadeias carbônicas menores (hemiceluse) e ainda de baixo peso moleculares que não conseguirão ser absorvida pelos animais, permitido assim maior facilidade de decomposição pela microbiota do solo (SINGH et al., 1991; HOLLAND et al., 1992), e permite aumentar a taxa de ciclagem de $\mathrm{N}$ resultante da deposição de urina e fezes (BAYER \& MIELNICZUCK, 1997), pois estão presentes em fração facilmente mineralizável, onde está mais acessível à absorção de plantas e microorganismos (ARCHER \& SMEINS, 1991; McNAUGHTON, et al., 1988; SINGH et al., 1991; BAUER et al., 1987) e a alta intensidade de pastejo pode aumentar a disponibilidade de $\mathrm{N}$, principalmente para cultivos nos anos subsequentes (UNKOVICH et al., 1998).

A decomposição rápida no período inicial pode ser explicada devido ao elevado conteúdo de componentes de baixo peso molecular tais como açúcares, aminoácidos e proteínas, sendo que, posteriormente em estágios mais avançados de decomposição tendem a diminuir devido à acumulação de componentes recalcitrantes, tais como lignina, taninos e celulose. Os animais em pastejo alteram a taxa de mineralização dos nutrientes devido à diminuição do tamanho das partículas vegetais através da mastigação e ruminação, e em consequência disso a ciclagem de nutrientes é acelerada (RUSSELLE, 1997).

Dessa forma, a quantidade de ciclagem de nutrientes pelo animal é definida pela intensidade de pastejo. Em geral, quanto mais animais por unidade de área maior será a ciclagem de nutrientes, porém haverá menor fixação de nutrientes em produto de origem animal por unidade de forragem ingerida, e ambas as situações são afetadas pela intensidade de pastejo (CARVALHO et al. 2010).

O sistema pecuário que envolve pastejo por bovinocultura de leite tem efeito marcante na ciclagem de $\mathrm{N} \mathrm{e}$ permitem a ciclagem através de suas excretas na ordem entre 75 a 95\% do $\mathrm{N}$ por eles ingerido, a extensão disto dependerá das taxas de fertilização do solo, da ingestão ou não de concentrados, da taxa de lotação da área, do tempo de pastejo e da composição botânica da pastagem (CUTTLE \& SCHOLEFIELD, 1995).

Dessa forma, o pastoreio quando realizado devidamente, com adequada taxa de lotação pode melhorar o rendimento de culturas subsequentes através da melhor estruturação do solo promovido pelo sistema radicular das pastagens e à maior ciclagem de nutrientes, em razão da deposição da urina e esterco animal e residual da forragem sobre a superfície do solo (TRACY \& DAVIS., 2009; CARVALHO et al., 2010), resultando em menor dependência do uso de insumos de fertilizantes, especialmente $\mathrm{N}$ (LOPES et al., 2009), uma vez que é o nutriente mais exigido em muitas culturas (FONTOURA, 2005), como o milho, onde os níveis de N, o tempo e métodos de aplicação são amplamente estudados em sistemas puramente agrícolas, mas com poucos estudos no sistema de produção integração lavoura-pecuária (SANDINI et al., 2011).

Pitta et al. (2013), trabalhando no arraçaomento de cabras da raça Boer, verificaram que o teor de $\mathrm{N}$ mineral no solo em áreas sem pastejo no final do ciclo foram menores nas camadas superficiais do solo (0-5 e 5-10 $\mathrm{cm})$ quando comparados aos tratamentos com pastejo, 
no período de inverno. Este mesmo trabalho observou que há maior cinética de decomposição da biomassa residual da aveia preta em sistema onde há pastejo em relação ao sistema não pastejado por cabras com rápida decomposição nos períodos iniciais e posterior decomposição lenta.

A intensidade de pastoreio tem grande influência sobre a quantidade total de resíduos orgânicos adicionados ao solo, condição que possibilita obter direta a relação entre altura do pasto e massa de folhas da forragem, e direcionar desta forma a ciclagem de $\mathrm{N}$ e $\mathrm{C}$ no sistema (SOUZA et al., 2008; LOPES et al., 2009).

Souza et al. (2008) observaram que após 44 dias de incubação, 64\% da matéria seca inicial do tratamento sem pastejo ainda permanecia sobre a superfície do solo, enquanto no mesmo período a decomposição da biomassa residual remanescente do tratamento com pastejo foi de 55\%. A diferença na decomposição da MS da biomassa residual entre os tratamentos com pastejo e sem tornou-se mais evidente após 195 dias de incubação, onde permaneceu 16 e $37 \%$ da matéria seca remanescente, respectivamente para os tratamentos com e sem pastejo.

O comportamento da liberação de $\mathrm{N}$ de resíduos da biomassa proveniente do tratamento com pastejo, permite melhor sincronização de demanda de $\mathrm{N}$ pelas plantas de milho, que ocorre entre 29 e 82 dias do ciclo (DUARTE et al., 2003). Esta disponibilidade gradual quando realizada o pastejo pode ser explicada em razão do consumo da biomassa vegetal e posterior transforamação no trato digestivo do animal, enquanto que na condição sem pastejo ocorre a preservação desta biomassa, o que configura dinâmica diferentes de $\mathrm{N}$ quanto a imobilização e mineralização pelos microorganismos e, consequentemente, diferentes velocidades de decomposição entre estes dois sistemas (SULC \& TRACY, 2007; TRACY \& ZHANG, 2008),

Souza et al. (2009) demonstraram que no final do período de incubação, $14 \%$ do nitrogênio foi liberado da biomassa sem pastejo, e $27 \%$ na biomassa residual com pastejo. Este comportamento também foi observado por Carvalho et al. (2010), onde demonstraram que o pastejo acelerou a taxa de decomposição da biomassa residual da aveia preta, bem como a liberação do nitrogênio do resíduo quando comparado com áreas não pastejadas.

Carvalho et al. (2010) demonstraram que o aumento na taxa de lotação, aumenta os retornos da excreta, acelerando as taxas de ciclagem de $\mathrm{N}$ e aumento do $\mathrm{N}$ no solo na forma mineral $\mathrm{N}_{-} \mathrm{NH}_{4}+$, que predominou sob o $\mathrm{N}-\mathrm{NO}_{3}$ - e que ao longo da integração lavoura-pecuária envolvendo a cultura da soja, o nitrogênio mineral do solo manteve-se elevado (100 kg/ha-1 $\mathrm{N})$, atingindo valores de próximos de $500 \mathrm{kgha}^{-1}$. E neste mesmo trabalho com intensidades de pastejo moderado há significativa redução na extração de nitrogênio mineral, associada com níveis maiores de liberação lenta de $\mathrm{N}$ na MOS.

Em intensidades de pastejo moderadas (pastagens anuais e temperadas manejadas a 20 e $40 \mathrm{~cm}$ de altura), houve um aumento em todo o estoque de C e N (total e particulado) de forma semelhante como ocorreu no tratamento sem pastejo. No entanto, na maior intensidade de pastagem (10 cm de altura), as perdas de $\mathrm{C}$ e $\mathrm{N}$ foram observadas após o terceiro ano do experimento (CARVALHO et al., 2010)

\section{Considerações Finais}

Para entender a ciclagem de nutrientes no sistema de produção ILP, há a necessidade de conhecer os resíduos culturais que permanecem na superfície do solo, os quais constituem importante reserva de nutrientes, cuja disponibilização pode ser rápida e intensa, ou lenta e gradual, conforme a interação entre os fatores climáticos, principalmente precipitação pluvial e temperatura, atividade macro e microbiológica do solo e qualidade e quantidade do resíduo.

Para que uma espécie seja eficaz na ciclagem de nutrientes deve haver sincronia entre o nutriente liberado pelo resíduo da planta de cobertura e a demanda da cultura de interesse comercial, cultivada em sucessão. Sendo que em alguns sistemas a liberação de nutrientes pode coincidir com a maior demanda nutricional da cultura quando se utiliza consorciação entre espécies, preferencialmente gramíneas e leguminosas, fator importante tanto do ponto de vista da produtividade como da redução do risco de contaminação ambiental via volatilização de amônia, lixiviação de nitrato e emissão de N2O.

Estima-se que $60 \%$ a $70 \%$ do $\mathrm{N}$ encontrado na biomassa vegetal seja reciclado e novamente absorvido pelas plantas no cultivo seguinte, daí a importância da consorciação e manutenção de grandes quantidades de palhada sobre o solo para fornecer este nutriente para a cultura sucessória.

A associação do sistema ILP com PD possibilita alta entrada de resíduo vegetal pelo uso de culturas e pastagens, o que permite suportar maior estoque de C orgânico total e N, especialmente na camada superficial em relação a sistemas de produção que não utilizam pastagens.

A taxa de decomposição e liberação de nutrientes em diversas espécies de cobertura é influenciada por vários fatores como relação $\mathrm{C} / \mathrm{N}$, condições climáticas como temperatura e umidade, leguminosas ou gramíneas, atividade macro e microbiológica do solo e qualidade e quantidade do resíduo. Essas características do resíduo podem permitir uma maior ou menor taxa de mineralização do nitrogênio.

Resíduos oriundos de culturas anuais e forragens pertencentes à famíla Poaceae produzem elevadas quantidades de biomassa que protegem o solo contra o impacto de chuvas, reduzindo o escoamento superficial de nutrientes e representam importantes fontes de matéria orgânica e nitrogênio para culturas subseqüente. Enquanto plantas 
de cobertura/pastagens pertencentes à família Fabaceae produz menores quantidades de palhada, mas, são altamente capacitadas em fixar biologicamente maiores quantidades de $\mathrm{N}$ atmosférico e contribuir substancialmente na redução do uso de fertilizantes nitrogenados em solos com fertilidade construída.

A entrada do animal no sistema produtivo modifica os fluxos entre os compartimentos, por haver ingestão de nutrientes, via consumo da forragem, sua digestão e posterior retorno ao sistema, ocorrendo à ciclagem dos nutrientes pelo material orgânico, o que resulta em nova dinâmica dos nutrientes entre os compartimentos do sistema.

A quantidade de ciclagem de nutrientes pelo animal é definida pela intensidade de pastejo. Em geral, quanto mais animais por unidade de área maior será a ciclagem de nutrientes, porém haverá menor fixação de nutrientes em produto de origem animal por unidade de forragem ingerida, e ambas as situações são afetadas pela intensidades de pastejo.

\section{Referências}

AITA, C.; GIACOMINI, S.J. Decomposição e liberação de nitrogênio de resíduos culturais de plantas de cobertura de solo solteiras e consorciadas. Revista Brasileira de Ciência do Solo, v.27, p.601-612, 2003.

AITA, C. et al. Plantas de cobertura de solo como fontes de nitrogênio ao milho. Revista Brasileira de Ciência do Solo, v.25, p.157-165, 2001.

AIDAR, H.; KLUTHCOUSKI, J. Evolução das atividades lavoureiras e pecuária nos cerrados. In: KLUTHCOUSKI, J.; STONE, L.F.; AIDAR, H. (Ed.). Integração lavoura pecuária. Embrapa Arroz e Feijão, p.25-58, 2003.

ALMEIDA, K.; CÂMARA, F.L.A. Produção de fitomassa e acúmulo de nitrogênio em espécies de adubos verdes de inverno. Revista Brasileira de Agroecologia, v.2, p.1224-1227, 2007.

ALVAREZ, S. et al. Whole-farm nitrogen cycling and intensification of crop-livestock systems in the highlands of Madagascar: An application of network analysis. Agricultural Systems, 2013. http://dx.doi.org/1 0.1016/j.ags y.2013.0 3.005

ALVARENGA, R. C. et al. Plantas de cobertura de solo para sistema plantio direto. Informe Agropecuário, Belo Horizonte, v. 22, n. 208, p. 2536. 2001.

AMADO, T.J.C. Manejo da palha, dinâmica da matéria orgânica e ciclagem de nutrientes emplantio direto. In: ENCONTRO NACIONAL DE PLANTIO DIRETO NA PALHA, 7., 2000, Ponta Grossa, PR. Anais... Ponta Grossa: FEBRAPDP, p.105-111, 2000.

ANDREOTTI, M. et al. Produção e tempo de decomposição de biomassa de plantas de cobertura em sistema plantio direto. In: REUNIÃO BRASILEIRA DE FERTILIDADE DO SOLO, 27., 2006, Bonito. Anais... Dourados: Embrapa Agropecuária Oeste/SBCS, v.1. (CD-ROM), 2006.

ANDRIOLI, I. Plantas de cobertura em pré-safra à cultura do milho em plantio direto, na região de Jaboticabal-SP. Tese (Livre-Docente) - Faculdade de Ciências Agrárias e Veterinárias, Universidade Estadual Paulista, Jaboticabal. 78 f. 2004.

ANDA. Asoociação Nacional para difusão de Adubos. Anuário Estatístico para do Setor de Fertilizantes, São Paulo: ANDA, 160p. 2009.

ANGHINONI, I. et al. Benefícios da integração lavoura-pecuária sobre a fertilidade do solo em sistema plantio direto. In: Da Fonseca, A.F.; Caires, E.F.; Barth, G. Fertilidade do solo e nutrição de plantas no sistema plantio direto. AEACG/Inpag: Ponta Grossa, p.272-309, 2011.

ARCHER, S.; SMEINS, F.E. Ecosystem-level processes. In: HEITSCHIMIDT, R.K. \& STUTH, J.W., eds. Grazing management: an ecological perspective. Portland, Timber Press, p.109-139, 1991.

ASSMANN, T. S. Rendimento de milho em área de integração lavoura pecuária sob o sistema plantio direto, em presença e ausência de trevo branco, pastejo e nitrogênio. Revista Brasileira de Ciência do Solo, v. 27, n. 4, p. 675-683, 2003.

BAETHGEN, W.E. Dinamica del nitrógeno en sistemas de rotacion cultivos-pasturas. Revista INIA de Investigaciones Agronómicas, v.1, n.1, p.325, 1992.

BALBINOT Jr. et al. Integração lavoura-pecuária: intensificação de uso de áreas agrícolas. Ciência Rural, v.39, n.6, p.1925-1933, 2009.

BARDUCCI, R. S. et al. Produção de Urochloa brizantha e Panicum maximum com milho e adubação nitrogenada. Archivos de Zootecnia, v. 58, n. 222, p. 211-222, 2009.

BAUER, A. Soil property comparisons in virgin grasslands between grazed and nongrazed 
management systems. Soil Science Society America Journal, v.51, 76-182p., 1987.

BAYER, C.; MIELNICZUCK, J. Características químicas do solo afetadas por métodos de reparo e sistemas de cultura. Revista Brasileira de Ciência do Solo, v.21, p.105-112, 1997.

BIERMAN, S. et al. Evaluation of nitrogen and organic matter balance in the feedlot as affected by level and source of dietary fiber. Journal Animal Science, v.77, p.1645-1653, 1999.

BODDEY, R.M. et al. Carbon accumulation at depth in Ferralsols under zero-till subtropical agriculture. Global Change Biology, v.16, n.2, p.784-795, 2010.

BOER, C.A. et al. Ciclagem de nutrientes por plantas de cobertura na entressafra em um solo de cerrado. Pesquisa Agropecuária Brasileira, v.42, p.1269-1276, 2007.

BORGHI, E. et al. Produtividade e qualidade das forragens de milho e de Brachiaria brizantha em sistema de cultivo consorciado. Revista Brasileira de Milho e Sorgo, v. 5, n. 3, p. 369-381, 2006.

BORTOLLI, M. A. de Influência de períodos de pastejo em trigo duplo propósito sobre a decomposição e liberação de nutrientes da palhada em sistema de integração lavourapecuária. Dissertação de Mestrado, Pato Branco: Universidade Tecnológica Federal do Paraná, 81p. 2010.

BRAZ, S.P. et al. Aspectos quantitativos do processo de reciclagem de nutrientes pelas fezes de bovinos sob pastejo em pastagem de Brachiaria decumbens na zona da Mata de Minas Gerais. Revista Brasileira de Zootecnia, v.31, n.2, p.858-865, 2002.

CALEGARI, A. et al. Impact of long term no-tillage and cropping system management. Agronomy Journal, v.100, n.4, p.1013-1019, 2009.

CANTARELlA, H.; DUARTE, A. P. Manejo da fertili $\neg$ dade do solo para a cultura do milho. In: GALVÃO, J. C. C.; MIRANDA, G. V. Tecnologia de Produção do Milho, p.139-182, 2004.

CARVALHO, J.L.N. et al. Impact of pasture, agriculture and crop-livestock systems on soil C stocks in Brazil. Soil Tillage Research, 110, 175-186, (2010a).

CARVALHO, P.C.F. et al. Managing grazing animals to achieve nutrient cycling and soil improvement in no-till integrated systems. Nutrient Cycling in Agroecosystems, v. 88, n. 2, p.259-273, 2010b.

CARVALHO, N.L.; ZABOT, V. Nitrogênio: Nutriente ou poluente? Revista Eletronica em Gestão, Educação e Tecnologia Ambiental. v.6, n.6, p.960974, 2012.

CAVALCANTE, M.A.B. Reciclagem de excreções animais na pastagem. 2001. Disponível em: www. forragicultura.com.br. Acesso em: 11/04/2013.

CORAZZA, E. J. et al. Comportamento de diferentes sistemas de manejo como fonte ou depósito de carbono em relação á vegetação de Cerrado. Revista Brasileira de Ciência do Solo, v.23, p.425432, 1999.

CORSI, M. e MARTHA JÚNIOR, G. B. Manutenção da fertilidade do solo em sistemas intensivos de pastejo rotacionado. In: SIMPÓSIO SOBRE MANEJO DA PASTAGEM, 14., Piracicaba SP, 1997. Anais... PEIXOTO, A. M et al. (eds.). Piracicaba: FEALQ. p.161-192, 1997.

COSTA, N. R. Adubação nitrogendada no consórcio milho/braquiárias e efeito sobre o feijão de inverno em sucessão no cerrado. Faculdade de Engenharia - UNESP - Campus de Ilha Solteira, (Mestrado Dissertação) Agronomia. Especialidade: Sistemas de Produção, 2010.

CRUSCIOL, C.A.C.; SORATTO, R.P. Nitrogen supply for cover crops and effects on peanut grown in succession under a no-till system. Agronomy Journal, v.101, p.40-46, 2009.

CRUSCIOL, C.A.C. et al. Taxas de decomposição e de liberação de macronutrientes da palhada de aveia preta em plantio direto. Bragantia, v.67, p.481-489, 2008.

CUNHA, J.F. et al. Balanço de nutrientes na agricultura brasileira. Instituto Internacional de Nutrição de Plantas, IPNI, Informações Agronômicas, n.130, 2010.

CUTTLE, S.P.; SCHOLEFIELD, D. Management options to limit leaching from grassland. Journal Contaminant Hydrology, v.20, p.299-312, 1995.

DUARTE, A. P. et al. Acúmulo de matéria seca e nutrientes em cultivares de milho originárias de clima tropical e introduzidas de clima temperado. Revista Brasileira de Milho e Sorgo, v.2, n.3, p.1-19, 2003. 
FLOSS, E. Benefícios da biomassa de aveia ao sistema de semeadura direta. Revista Plantio Direto, Passo Fundo, v.57, n.1, p.25-29, 2000.

FONTOURA, S. M. V. Adubação nitrogenada na cultura do milho em entre rios, Guarapuava, PR. Fundação Agrária de Pesquisa Agropecuária, p.94. 2005.

FREIRE, F.M. et al. Manejo da fertilidade do solo em sistema plantio direto. Informe Agropecuário, v.22, n.208, p.49-62, 2001.

GAMA-RODRIGUES, A.C. et al. Decomposição e liberação de nutrientes de resíduos culturais de plantas de cobertura em Argissolo VermelhoAmarelo na região Noroeste Fluminense (RJ). Revista Brasileira de Ciência do Solo, v.31, p.14211428, 2007.

GARAY, A.H. et al. Nitrogen fertilization and stocking rate affect stargrass pasture and cattle performance. Crop Science, v.44, n.4, p.1348-1354, 2004.

GIACOMINI, S.J. et al. Imobilização do nitrogênio amoniacal de dejetos líquidos de suínos em plantio direto e preparo reduzido do solo. Revista Brasileira de Ciência do Solo, v.33, p.41-50, 2009.

GIACOMINI, S.J.; AITA, C. Simulating the effects of $\mathrm{N}$ availability, straw particle size and location in soil on C and N mineralization. Plant Soil, v.301, p.289-301, 2007.

GIACOMINI, S.J. et al. Matéria Seca, relação C/N e acúmulo de nitrogênio, fósforo e potássio em misturas de plantas de cobertura de solo. Revista Brasileira de Ciência do Solo, v.27, p.325-334, 2003b.

GIACOMINI, S. J. et al. Liberação de fósforo e potássio durante a decomposição de resíduos culturais em plantio direto. Pesquisa Agropecuária Brasileira, v. 38, n.9, p.1097-1104, 2003.

GODSEY, C.B. et al. Changes in soil pH, organic carbon, and extractable aluminum from crop rotation and tillage. Soil Science Society of America Journal, v.71, n.5, p.1038-1044, 2007.

GOMES JUNIOR, F. G. Nitrogênio no feijoeiro em sistema de plantio direto sobre diferentes palhadas: produtividade, composição química e qualidade fisiológica das sementes.. (Dissertação Mestrado) Faculdade de Engenharia, Universidade Estadual Paulista, Ilha Solteira, 106 f, 2006.
HAYNES, R.J.; WILLIAMS, P.H. Nutrient cycling and soil fertility in the grazed pasture ecosystem. Advanced Agronomy, v.49, n.1, p.119-199, 1993.

HEINRICHS, R. et al. Cultivo consorciado de aveia e ervilhaca: relação $\mathrm{C} / \mathrm{N}$ da fitomassa e produtividade do milho em sucessão. Revista Brasileira de Ciência do Solo, v.25, p.331-340, 2001.

HOLLAND, E.A. et al. Physiological responses of plant populations to herbivory and their consequences for ecosystem nutrient flow. America Natural, v.140, p.685-706, 1992.

JANTÁLIA, C.P. et al. Fluxes of nitrous oxide from soil under different crop rotations and tillage systems in the South of Brazil. Nutrient Cycling in Agroecosystems, v.82, n.2, p.161-173, 2008.

KLUTHCOUSKI, J. et al. Manejo antecipado do nitrogênio nas principais culturas anuais. Santo Antônio de Goiás: Embrapa Arroz e Feijão, 63p. 2005. (Documentos / Embrapa Arroz e Feijão, 188).

KOCHHANN, R.A. et al. Rendimento de grãos de trigo cultivado em seqüência ao adubo verde nabo forrageiro. Passo Fundo: Embrapa Trigo, 12p. 2003. (Embrapa Trigo. Comunicado Técnico Online, 116). Disponível em: <http://www.infoteca. cnptia.embrapa.br/handle/doc/852298>. Acesso em: 10/4/2013.

KOZELINSKI, S.M. Produção de trigo duplo propósito e ciclagem de nutrientes em sistema de integração lavoura pecuária. (Dissertação de Mestrado) Pato Branco: Universidade Tecnológica Federal do Paraná, 90p. 2009.LANDERS, J. N. Tropical crop-livestock systems in conservation agriculture: the Brazilian experience. In: Integrated Crop Management. Rome: Food and Agriculture Organization of the United Nations-FAO, v. 5, p.92 2007.

LANDERS, F. N. Fascículo de experiências de plantio direto no cerrado. Goiânia: APDC, 261p. 1995.

LARA-CABEZAS, W.A.R. et al. Balanço da adubação nitrogenada sólida e fluida de cobertura na cultura de milho, em sistema de plantio direto no Triângulo Mineiro (MG). Revista Brasileira de Ciência do Solo, v.24, p.363-376, 2000.

LIMA, E. V. et al. Espécies para cobertura e qualidade dos resíduos vegetais na implantação do sistema de plantio direto em região de inverno seco. Revista Brasileira de Milho e Sorgo, v. 4, n. 2, p.180-194, 2005. 
LIMA, J.D. et al. Comportamento do nabo forrageiro (Raphanus sativus L.) e da nabiça (Raphanus raphanistrum L.) como adubo verde. Pesquisa Agropecuária Tropical, v.37, p.60-63, 2007.

LIU, T. et al. Grazing intensity effects on soil nitrogen mineralization in semi-arid grassland on the Loess Plateau of northern China. Nutrient Cycling Agroecosystems, v.91, p.67-75, 2011.

LOSS, A. et al. Agregação, carbono e nitrogênio em agregados do solo sob plantio direto com integração lavoura-pecuária. Pesquisa Agropecuária Brasileira, v.46, n.10, p.1269-1276, 2011.

LOSS, A. et al. Carbon and Nitrogen Content and Stock in No-Tillage and Crop-livestock Integration Systems in the Cerrado of Goias State, Brazil. Journal of Agricultural Science, v. 4, n.8; 2012.

LOPES, M. L. T. et al. Sistema de integração lavourapecuária: efeito do manejo da altura em pastagem de aveia preta e azevém anual sobre o rendimento da cultura da soja. Revista Ciência Rural, v.39, n.5, p.1499-1506, 2009.

LUIZAO, R.C. et al. Seasonal variation of soil microbial biomass-the effect of clearfelling a tropical rainforest and establishment of pasture in the central Amazon. Soil Biologycal Biochemistry, v.24, p.805-813, 1992.

LUPWAYI, N. Z. et al. Phosphorus release during decomposition of crop residues under conventional and zero tillage. Soil Tillage Research, v.95, p.231239, 2007.

MAGALHÃES, R.T. Evolução das propriedades físicas e químicas de solos submetidos ao manejo pelo sistema barreirão, (Dissertação Mestrado) Universidade Federal de Goiás, Goiânia, 86 f. 1997.

MALAVOLTA, E. Elementos de nutrição de plantas. São Paulo: Agronômica Ceres, 251p. 1980.

MARCHAO, R. et al. Carbon and nitrogen stocks in a Brazilian clayey Oxisol: 13-year effects of integrated crop livestock management systems. Soil Tillage Research, v.103, p.442-450, 2009.

MARTHA JÚNIOR, G. B. et al. Benefícios bioeconômicos e ambientais da integração lavourapecuária. Planaltina: EMBRAPA, 26 p. 2006. (Documentos, 154).

MARTHA JÚNIOR, G. B. et al. A produção animal em pastagens no Brasil: uso do conhecimento técnico e resultados. In: SIMPÓSIO SOBRE MANEJO DA PASTAGEM, Piracicaba. Anais... Piracicaba: FEALQ, p.87-137. 2006.

MARTHA JÚNIOR, G.B.; VILELA, L. Resultado econômico e estratégias de intensificação da adubação de pastagens. In: MARTHA JÚNIOR, G.B.; VILELA, L.; SOUSA, D.M.G. (Ed.). Uso eficiente de corretivos e fertilizantes em pastagens. Planaltina: Embrapa Cerrados, Cap.3, p.69-92. 2007.

McNAUGHTON, S.J. et al. Large mammals and process dynamics in African ecosystems. Biological Sciences, v.38, p.794-800, 1988.

MELLO, F. A. de et al. Fertilidade do solo. São Paulo: Nobel, 1989.

MENEZES, L.A.S. et al. Produção de fitomassa de diferentes espécies, isoladas e consorciadas, com potencial de utilização para cobertura do solo. Bioscience Journal, v.25, p.7-12, 2009.

MORAES, A. et al. Integrated croplivestock systems in the subtropics. In: Moraes A, Carvalho PCF et al (eds) Proceedings of the international symposium on integrated crop-livestock systems. Curitiba, 2007.

NASCIMENTO, R.S.; CARVALHO, N.L. Integração Lavoura-Pecuária. Monografiias Ambientais. v.4, n4, p.828-847, 2011.

OLIVEIRA, T.K. et al. Plantas de cobertura e seus efeitos sobre o feijoeiro em plantio direto. Pesquisa Agropecuária Brasileira, v.37, p.1079-1087, 2002.

PETERSON, R. G. et al. The distribution of excreta by freely grazing cattle and its effect on pasture fertility: I excretal distribution. Agronomy Journal, v.48, p.440-444, 1956.

PITTA et al. Decomposition and nitrogen release in areas with and without grazing and its influence on corn. Ciências Agrárias, v.34, n.2, p.905-920, 2013. PRIMAVESI, O. et al. Qualidade mineral e degrabilidade potencial de adubos verdes conduzidos sobre Latossolos, na região tropical de São Carlos, SP, Brasil. Revista de Agricultura, v.77, n.1, p.89-102, 2002.

RAIJ, B. van; et al. Recomendações de adubação e calagem para o estado de São Paulo. Campinas: IAC, 285 p. 1997. (Boletim Técnico, 100).

ROSOLEM, C. A. et al. Potássio lixiviado da palha de 
aveia-preta e milheto após a dessecação química. Pesquisa Agropecuária Brasileira, v.42, n.8, p.11691175, 2007.

ROSOLEM, C.A. et al. Lixiviação de potássio da palha de espécies de cobertura de solo de acordo com a quantidade de chuva aplicada. Revista Brasileira de Ciência do Solo, v.27, p.355-362, 2003.

RUSSELLE, M. P. Nutrient cycling in pasture. In: SIMPÓSIO INTERNACIONAL SOBRE PRODUÇÃO ANIMAL EM PASTEJO, 1997, Viçosa - MG. Anais... GOMIDE, J. A. (ed.). Viçosa: UFV, p. 235-266. 1997.

SALTON, J.C. Dinâmica do carbono em sistemas de integração lavoura-pecuária. In: Moraes A, Carvalho PCF et al (eds) Proceedings of the international symposium on integrated croplivestock systems. Curitiba, 2007.

SANTOS, H.P. dos; et al. Fertilidade e teor de matéria orgânica do solo em sistemas de produção com integração lavoura e pecuária sob plantio direto. Revista Brasileira de Ciências Agrárias, v.6, n.3, p.474-482, 2011.

SANDINI, I. E. et al. Efeito residual do nitrogênio na cultura do milho no sistema de produção integração lavoura-pecuária. Revista Ciência Rural, v.41, n.8, p.1315-1322, 2011.

SANDINI, I. E. et al. Grazing intensity effects on litter decomposition and soil nitrogen mineralization. Journal Range Management, v.47, p.444-449, 1994.

SINGH, R. S. et al. Nitrogen mineralization in dry tropical savanna: Effects of burning and grazing. Soil Biology and Biochemistry, v.22, p.835-838, 1991.

SILVA, C. P.; MONTEIRO, F. A. Morfogênese e produção de biomassa do capim-tanzânia adubado com nitrogênio e cálcio. Revista Brasileira de Zootecnia, v.36, n.2, p.335-342, 2007.

SILVEIRA, P. M. et al. Adubação nitrogenada no feijoeiro cultivado sob plantio direto em sucessão de culturas. Pesquisa Agropecuária Brasileira, v.40, n.4, p.377-381, 2005.

SOUZA, E.D. et al. Biomassa microbiana do solo em sistema de integração lavoura-pecuária em plantio direto, submetido a intensidades de pastejo. Revista Brasileira de Ciência do Solo, v.34, p.79-88, 2010.
SOUZA, E.D. et al. Estoques de carbono orgânico e de nitrogênio no solo em sistema de integração lavoura-pecuária em plantio direto, submetido a intensidades de pastejo. Revista Brasileira de Ciência do Solo, v.33, p.1829-1836, 2009.

SOUZA, E. D. et al. Carbono orgânico e fósforo microbiano em sistema de integração agriculturapecuária submetido a diferentes intensidades de pastejo em plantio direto. Revista Brasileira de Ciência do Solo, v.32, n.3, p.1273-1282, 2008.

SPAIN, J. M.; SALINAS, J. G. A reciclagem de nutrientes nas pastagens tropicais. In: REUNIÃO BRASILEIRA DE FERTILIDADE DO SOLO, 1985, Ilhéus. Anais... Ilhéus: S.n., p.159-299. 1985.

SPERA, S.T. et al. Integração lavoura e pecuária e os atributos físicos de solo manejado sob sistema de plantio direto. Revista Brasileira de Ciência do Solo, v. 33, p.129-136, 2009.

STUTE, J.K.; POSNER, J.L. Synchrony between legume nitrogen release and corn demand in the upper Midwest. Agronomy Journal, v.87, p.10631069, 1995.

SULC, R. M.; TRACY, B. F. Integrated crop-livestock systems in the U.S. corn belt. Agronomy Journal, v.99, n. 2, p.335-345, 2007.

TORRES, J.L.R. et al. Decomposição e liberação de nitrogênio de resíduos culturais de plantas de cobertura em um solo de cerrado. Revista Brasileira de Ciências do Solo, v.29, p.609-618, 2005.

TORRES, J. L. R. et al. Produção de fitomassa por plantas de cobertura e mineralização de seus resíduos em plantio direto. Pesquisa Agropecuária Brasileira, v. 43, n.3, p.421-428, 2008.

TRACY, B. F.; DAVIS, A. S. Weed biomass and species composition as affected by an integrated croplivestock system. Crop Science, v.49, n.4, p.15231530, 2009.

TRACY, B. F.; ZHANG, Y. Soil compaction, corn yield response, and soil nutrient pool dynamics within an integrated croplivestock system in Illinois. Madison, v.48, n.3, p.1211-1218, 2008.

VIOLA, R. et al. Adubação verde e nitrogenada na cultura do trigo em plantio direto. Bragantia, v.72, n.1, p.90-10, 2013.

VITOUSEK, P.M. Nutrient imbalances in agricultural development. Science Magazine, v. 324, p.1519- 
1518, 2009.

VOSS, M. et al. Ervilha forrageira como adubo verde para o trigo: resultados preliminares. Passo Fundo: Embrapa Trigo, 5p. 2004. (Embrapa Trigo. Comunicado Técnico Online, 139).

ULIAN, N.A. et al. Tempo de decomposição de massa seca de espécies forrageiras em função de épocas de semeadura no cerrado. In: REUNIÂO BRASILEIRA DE FERTILIDADE DO SOLO E NUTRIÇÃO DE PLANTAS (FERTBIO 2010), 29, 2010, Guarapari/ES. Anais... Viçosa, MG: SBCS, 2010. (CD-ROM).

ULIAN, N.A. et al. Tempo de decomposição de massa seca de espécies forrageiras em função de épocas de semeadura na safrinha em região de cerrado. In: REUNIÃO BRASILEIRA DE FERTILIDADE DO SOLO E NUTRIÇÃO DE PLANTAS (FERTBIO 2008), 28, 2008, Londrina. Anais... Viçosa, MG: SBCS, 2008.

UNKOVICH, M. et al. Effects of grazing on plant and soil nitrogen relations of pasture crop rotations. Australian Journal Agricultural Research, v.49, p.475-485, 1998.

YAMADA, T.; LOPES, A.S. Balanço de nutientes na agricultura brasileira. Informações Agronômicas, Piracicaba, n.84, 8p.1998. (Encarte Técnico).

WENDLING, A. et al. Recomendação de adubação nitrogenada para trigo em sucessão ao milho e soja sob sistema plantio direto no Paraguai. Revista Brasileira de Ciência do Solo, v.31, p.985-994, 2007.

WIEDER, R.K.; LANG, G.E. A critique of the analytical methods used in examining decomposition data obtained from litter bags. Ecology, v.63, p.1636-1642, 1982.

WILLIANS, P.H.; HAYNES, R.J. Comparison of initial wetting pattern, nutrient concentrations in soil solution and the fate of N-15-labelled urine in sheep and cattle urine patch areas of pasture soil. Plant Soil, v.162, p.49-59, 1994.

WILKINSON, S. R.; LOWERY, R. W. Cycling of mineral nutrients in pasture ecosystems. Chemistry and Biochemistry of herbage, v.2, p. 247315, 1973.

WUTKE, E.B. Adubação verde: manejo da fitomassa e espécies utilizadas no Estado de São Paulo. In: WUTKE, E.B.; BULISANE, E.A.; MASCARENHAS, H.A.A. Campinas: Instituto Agronômico, p.17-29. 1993. (IAC. Documentos, 35). 